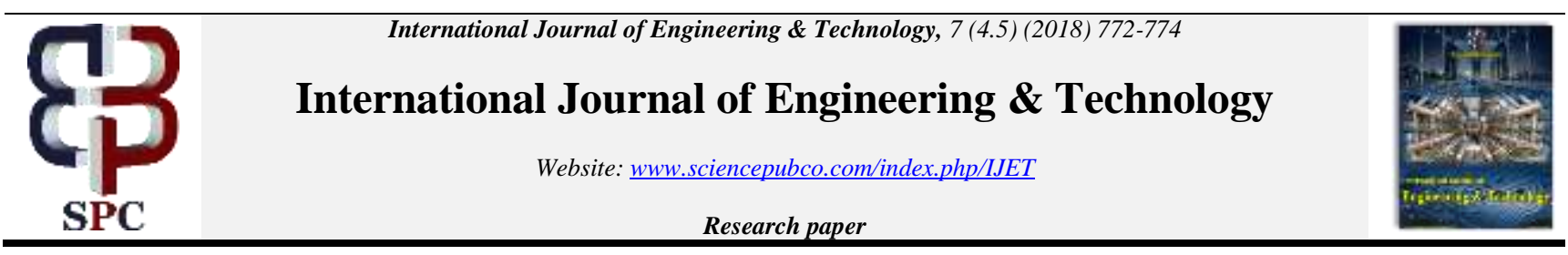

\title{
Composite braking module for an electric vehicle
}

\author{
Bharath K. R ${ }^{1}$, Sreenivasan M. K*1, Gokul Sivaraman ${ }^{1}$, Bededala Vineeth Kumar Reddy ${ }^{1}$ \\ ${ }^{1}$ Department of Electrical and Electronics Engineering, Amrita Vishwa Vidyapeetham, Amritapuri, Kollam, India, 690525 \\ *Corresponding author E-mail: bharathkr@am.amrita.edu
}

\begin{abstract}
The efficycle, is a hybrid tricycle which runs on manual and electric power. This paper proposes a method to design a braking load to dissipate the excess energy produced when there is no more requirement for the battery to be charged by regenerative braking. This module was designed for an operating voltage of $8 \mathrm{~V}$, resistance value of $0.16 \mathrm{ohm}$ and with a maximum current capacity of $200 \mathrm{~A}$. This resistor was coupled with a buck converter to step down the voltage across the battery to a value convenient for operation of the dissipation resistor.
\end{abstract}

Keywords: Use about five key words or phrases in alphabetical order, Separated by Semicolon.

\section{Introduction}

Regenerative braking is a technology now predominant in almost all the electric vehicles in the market today. This technology helps in recovering the energy wasted as heat during friction braking. This in turn helps in recharging the batteries and then using this free energy to run the vehicle whenever required. [1] presents an energy recovery system with feedback to the distribution grid based on a new converter topology. In the last few decades, there has been a renewed interest in electric vehicles due to the harmful effects of fossil fuels on the environment. [2-3] discusses the design methodology and the technology used to manufacture a solar Electric Vehicle that can be commercialized for the benefit of the society. This renewed interest has also led to developments in the various other areas of energy sector where study on feasibility of various renewable energy options has been performed as discussed in [4]. Similarly, as an advancement in renewable technologies, [5] deals with the operation and control of a grid connected PV system with a nonlinear load.

A frequent problem encountered during regenerative braking is a situation where the battery gets over charged. Every regenerative brake should have a mechanism to channel this excess energy by converting it to some other form. One such mechanism is the inclusion of a heat dissipating resistor to direct the excess energy to the environment in the form of heat energy. These resistors are like heating coils used in stoves which can withstand very high temperatures without getting damaged. This method of electrical braking involving a heat dissipating resistor during overcharge is called composite braking. [6] has brought the totally unused energy during braking in the limelight and paved the way to utilize this energy in a fruitful manner. [7] a multi-objective optimization problem is solved based on three primary conflicting objectives, namely minimization of deceleration duration, maximization of regenerative braking energy and minimization of jerk. A Braking force distribution strategy for an all-wheel-drive electrified vehicle with a single electric motor, based on the estimation of the tire-road friction coefficient $(\mu)$ using a fuzzy logic estimation approach is discussed in [8]. While [9] has analyzed the potential for regeneration in Swedish car driving by applying a model for a normalized vehicle to a highly detailed and representative data set of individual car movements for privately driven cars in Sweden.

The brake resistors are widely used in locomotives, heavy machines, elevators and other devices. To further exploit the potential of brake energy regeneration, brake resistors can be introduced into regenerative braking system of electrified vehicles. A new type of regenerative braking system with a brake resistor applied is proposed and researched in [10]. [11] mainly research on energy regeneration for the electric vehicle, analyze regeneration energy of electric vehicles in the process of braking, how we can recovery more efficient vehicles in the energy generated during braking. In [12], aiming at micro electric vehicle (EV), the operation principle of a control system of braking energy regeneration was analyzed, structure design scheme was proposed, the circuit of electronic control system was designed, and the method of operation pattern recognition and control of electronic control system was put forward. While in [13], the main properties that have influence on brake energy regeneration are analyzed.

On the basis of analysis and comparison of various types regenerative braking system, [14] presents a new combination control strategy, the target for the braking system controller design is to maintain two kinds of braking torque work together harmoniously to assure the braking safety of vehicle and maintain a sense of comfort for driver.

A new simplified methodology has been proposed in [15] to extract the power from the wheels into the battery by operating the Induction Motor in the generating mode even while the brakes are applied.

\section{The problem of over charging}

Over charging is a very common problem in batteries. This is something to be concerned about and should be addressed in every possible way. Over charged batteries may heat up and may even explode. This may lead to distortion in its shape and size due to bulging in $\mathrm{Li}$-ion or acid spillage in case of lead acid batteries. High voltages may also exhaust the battery, reducing its capacity over time. Thus, it may lead to irreversible damage to the battery. Since 
batteries are composed of chemicals, over charging may lead to permanent changes in charge and discharge rates. This will ultimately lead to increased vehicle charging time and reduced vehicle range.

\section{Detecting the problem}

There are many indications of a battery over charge. These indications can be used for detecting the anomaly and accordingly a protection scheme can be designed. Overheating due to overcharging can be detected using temperature sensors, over voltage of the battery can be detected using voltage sensors. These sensor values have been given to a microcontroller as its inputs. The micro controller then uses these inputs to generate signals which trigger relays and gate driver circuits accordingly, connecting the heat dissipating resistor across the circuit. This heat dissipating resistor can then be used to dissipate the excess energy and brake the vehicle by acting as a load to the alternator.

\section{Buck converter design}

A buck converter has been used to step down the voltage from the battery to the operating voltage of the resistor. The motor is rated at 400 watts. Assuming a power of $400 \mathrm{~W}$ to be dissipated across the resistor and a current of $50 \mathrm{~A}$ in the worst case scenario,

$400=\mathrm{V} \times 50$

$\mathrm{V}=8 \mathrm{~V}$

Therefore, the buck converter has to be designed to step down the voltage from battery voltage (i.e. $55 \mathrm{~V}$ when fully charged) to $8 \mathrm{~V}$. A simple buck converter topology has been adopted for this purpose. The Inductor value was estimated using this formula,

$$
L=\frac{V_{\text {OUT }} \times\left(V_{I N}-V_{\text {OUT }}\right)}{\Delta I_{L} \times f_{s} \times V_{I N}}
$$

$\mathrm{VOUT}=8 \mathrm{~V}$

$\mathrm{V}_{\mathrm{IN}}=55 \mathrm{~V}$

$\mathrm{Fs}_{\mathrm{S}}=50 \mathrm{kHz}$

$\Delta \mathrm{I}_{\mathrm{L}}=0.3 \times 50=15 \mathrm{~A}$

So, $\mathrm{L}=10 \mu \mathrm{H}$

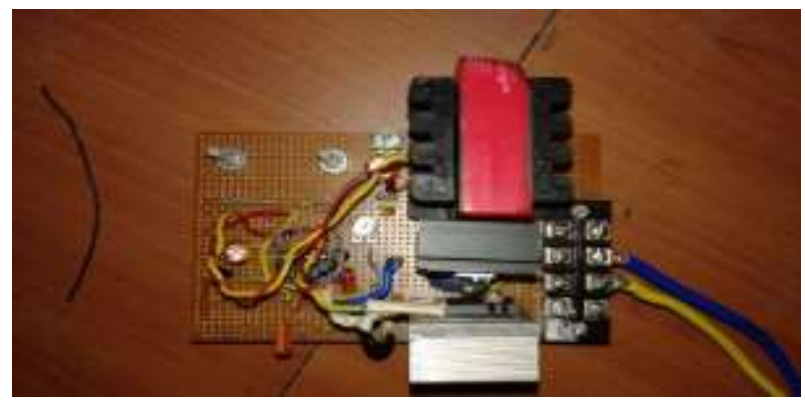

Fig. 1: Buck Converter.

\section{Resistor design}

Resistance required for an application of $8 \mathrm{~V}$ and $50 \mathrm{~A}$

Current $=8 / 50=0.16 \Omega$

Nichrome heating coils were used to build the resistor for this purpose. These heating coils were the ones used for domestic purpose in cooking stoves. They were rated for domestic application, i.e. $230 \mathrm{~V}$ and $2000 \mathrm{~W}$

So, current through each strip at rated power will be,

$\mathrm{I}=2000 / 230=8.69 \mathrm{~A}$

Accordingly, the resistance can be calculated to be,

$\mathrm{R}=230 / 8.69=26.46 \Omega$

This is the resistance of one strip of coil, i.e. $50 \mathrm{~cm}$.

By arranging strips of this coil in parallel to produce a resistance of $0.16 \Omega$, we can construct the resistor design.

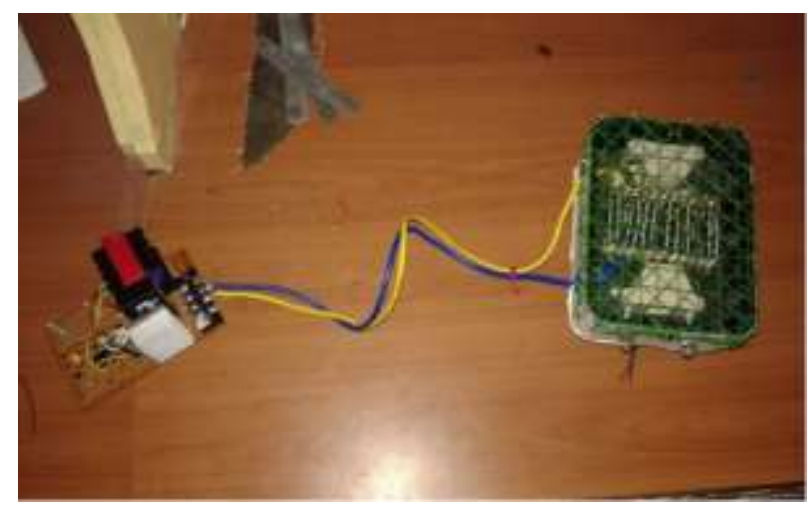

Fig. 2: Buck Converter Along with the Dynamic Load

\section{Boost converter design}

A boost converter has been used to step up the voltage from the motor rectifier to the operating voltage of the battery.

So, the boost converter has to be designed to step up the voltage from motor rectifier (i.e. $48 \mathrm{~V}$ at maximum speed) to $55 \mathrm{~V}$.

A simple boost converter topology has been adopted for this purpose.

The Inductor value was estimated using this formula,

$$
L=\frac{V_{I N} \times\left(V_{\text {OUT }}-V_{I N}\right)}{\Delta I_{L} \times f_{s} \times V_{\text {OUT }}}
$$

VOUT $=55 \mathrm{~V}$

$\mathrm{V}_{\mathrm{IN}}=2 \mathrm{~V}$ to $48 \mathrm{~V}$

$\mathrm{F}_{\mathrm{S}}=50 \mathrm{kHz}$

$\Delta \mathrm{I}_{\mathrm{L}}=0.3 \times 10=3 \mathrm{~A}$

So, $\mathrm{L}=41 \mu \mathrm{H}$

\section{Working of composite braking}

This system consists of the BLDC motor, the three-phase rectifier module, boost converter, battery bank, buck converter and a BLDC motor drive.

The three-phase rectifier module was designed using three single phase rectifier modules.

When the throttle is switched ON, the motor starts rotating. But when the brake is applied, the supply from the battery is cut off and the switch to the braking module is closed. Hence the power flows through the three-phase rectifier and then it steps up the voltage to supply the power at an optimum voltage to the battery bank so as to charge it.

The charging and discharging rate and instant is decided by the status of the throttle. The voltage of the battery is constantly monitored using a comparator, and if it exceeds beyond $55 \mathrm{~V}$, the PWM to the buck converter is switched $\mathrm{ON}$ and the excess power from the 
BLDC motor-generator is dissipated across the heat dissipating resistor.

The switching between converters is facilitated by using a relay logic. Such that when throttle is given, a relay acts as switch to cut off the dynamic braking system and connects the battery bank to the BLDC drive, and otherwise functions to enable dynamic braking. The driver is provided with a manual switch with which he/she can manually decide to include or exclude the dynamic brake.

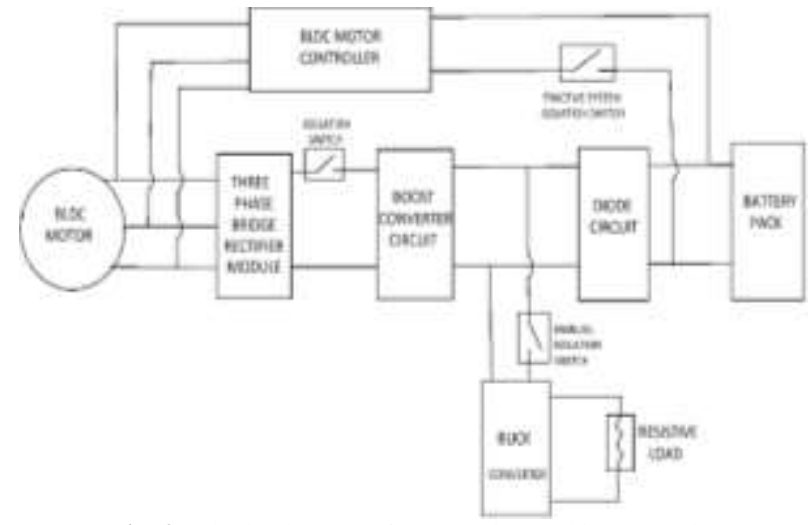

Fig. 3: Block Diagram of Composite Braking Module.

\section{Application results}

The buck converter and the resistor were designed and tested for different values of current. The resistor proved capable of withstanding the elevated temperatures and currents. This module was successfully implemented in the vehicle.

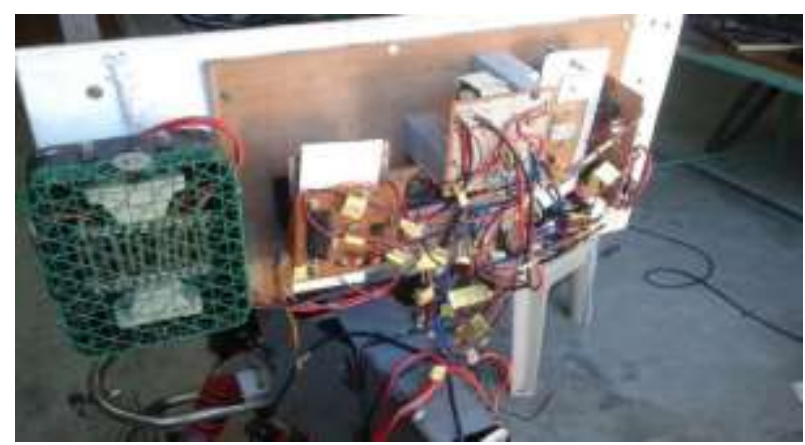

Fig. 4: Vehicle Implementation.

\section{Conclusion}

The composite braking module can reduce the wear and tear of the EV by providing consistent and better control over braking. Composite braking further increases the reliability as it protects the battery from overcharging.

\section{References}

[1] Harkaitz Ibaiondo, Asier Romo, 'Kinetic Energy Recovery on Railway Systems with Feedback to the Grid', 14th International Powe Electronics and Motion Control Conference, EPE-PEMC, pp 9497H. Poor, an Introduction to Signal Detection and Estimation, New York: Springer-Verlag, 1985, ch. 4. (Book Chapter).

[2] Ganesha Udupa and Josh Freeman, "Light weight multipurpose solar powered electric vehicle", Patent No: 4959/CHE/2013 Dated $01 / 11 / 2013$

[3] Ganesha Udupa, Josh Freeman, Vikas Nimbewal, Rajesh Kumar Choudhary, Swoop Sasikumar, Sreeraj V Nair, 'Design and Manufacture of Amrita Surya Vahini - A Solar Auto Rickshaw', 2016 International Conference on Robotics and Automation for Humanitarian Applications (RAHA).I. Çolak, E. Kabalci, R. Bayindir R. and S. Sagiroglu, "The design and analysis of a 5-level cascaded voltage source inverter with low THD", 2nd PowerEng Conference, Lisbon, pp. 575-580, 18-20 March 2009. (Conference Paper)
[4] Amrita Sharma, Bura Pramod, R. K Singh, R.Mahanty, 'Community development and energy equality: Experiences from micro hydro implementation in a tribal settlement in India', Humanitarian Technology Conference (R10-HTC), 2016 IEEE Region 10.

[5] Vishnu Prasad, Jayasree P R, Sruthy V, 'Hysteresis Current Controller for a micro-grid application', 2016 International Conference on Energy Efficient Technologies for Sustainability (ICEETS).

[6] S Mandal, M R I Sarker, M S Rahman, M R A Beg, 'An Analysis of Braking Energy Regeneration in Electric Vehicles', International Journal of Renewable Energy Research S. Mandal et al., Vol.7, No.3, 2017.

[7] Debasri Chakraborty, Arup Kr Nandi, 'Finding optimal driving strategy of electric vehicle during deceleration with serial regenerative braking', 2016 IEEE 7th Power India International Conference (PIICON).

[8] Deepak Paul, Efstathios Velenis, Dongpu Cao, 'optimal $\mu$-Estimation-Based Regenerative Braking Strategy for an AWD HEV', IEEE Transactions on Transportation Electrification (Volume: three, Issue: one, March 2017).

[9] Lars-Henrik Kullingsjö, Sten Karlsson, 'The possibility for energy regeneration by electrification in Swedish car driving', 2013 World Electric Vehicle Symposium and Exhibition (EVS27).

[10] Li Yutong, Zhang Junzhi, Lv Chen, Kong Decong, He Chengkun, 'Research of Regenerative Braking System for Electrified Buses Equipped with a Brake Resistor', 2013 IEEE Vehicle Power and Propulsion Conference (VPPC).

[11] Xiao Hua-qiao, Liu San-min, Wang Zhi-jie, Sun Xia, 'Efficiency optimization of energy regeneration for electric vehicle', 2011 International Conference on Electronics, Communications and Control (ICECC).

[12] Jinyu Qu, Liyan Liang, Zhongyu Yang, 'Operation Pattern Recognition and Control for Super Capacitor Braking Energy Regeneration System of Micro EV', 2009 Second International Symposium on Computational Intelligence and Design.

[13] Jingang Guo, Junping Wang, Binggang Cao, 'Regenerative braking strategy for electric vehicles', 2009 IEEE Intelligent Vehicles Symposium.

[14] Dong Peng, Jianwu Zhang, Chengliang Yin, 'Regenerative braking control system improvement for parallel hybrid electric vehicle', 2006 International Technology and Innovation Conference (ITIC 2006).

[15] Amrit Anand Mahapatra, Tanmaya Pradhan, 'Electrical braking with improved energy regeneration in induction machine drive', 2016 International Conference on Recent Advances and Innovations in Engineering (ICRAIE). 